\title{
Lateralized warning tones produce typical irrelevant-location effects on choice reactions
}

\author{
ROBERT W. PROCTOR \\ Purdue University, West Lafayette, Indiana \\ and \\ DAVID F. PICK \\ Purdue University Calumet, Hammond, Indiana
}

\begin{abstract}
Simon, Acosta, and Mewaldt (1975) reported an experiment in which a $200-\mathrm{Hz}$ warning-tone, presented in the left or right ear, was followed by an imperative stimulus of $500 \mathrm{~Hz}$ in either ear, to which a left- or right-key press was to be made. Simon et al. found a correspondence effect for warning location and response location (i.e., faster reactions when warning and response locations corresponded than when they did not) when the stimulus-response mapping was incompatible but not when it was compatible. These findings stand in contrast to typical results of (1) a correspondence effect for irrelevant location information when the mapping is compatible and (2) a reversed correspondence effect (i.e., faster responses when stimulus and response location do not correspond) when the mapping is incompatible. We conducted a direct replication of Simon et al.'s experiment and another experiment that differed only in the imperative stimulus being visual, in order to determine whether there are unique aspects of their method that yield atypical results. Our results failed to replicate those reported by Simon et al. but instead showed the patterns of correspondence effects typically found with other procedures, suggesting that the warning-signal method produces irrelevant-location effects consistent with those produced by other methods.
\end{abstract}

In a two-choice reaction task, two responses (usually left- or right-key presses) are assigned to two stimuli (e.g., low- or high-pitch tones; red or green circles). The subject is to respond as rapidly as possible on a trial by making the response assigned to the stimulus that is presented. In a series of seminal studies beginning in the late 1960s (Simon \& Rudell, 1967), Simon and his colleagues demonstrated that when the stimulus can occur in either a left or a right location-but stimulus location is irrelevant to the task (e.g., the correct response is determined by the color of a visual stimulus)--performance is nevertheless affected by the location in which the stimulus occurs. Reaction times (RTs) are faster when the stimulus location corresponds to the location of the assigned response than when it does not. Using the example of color stimuli, if red is assigned to the left response and green to the right response, RT is shorter when the red stimulus occurs in the left location and the green stimulus occurs in the right location than when these location relations are reversed. This phenomenon has come to be called the Simon effect, and it is sometimes called the spatial Stroop effect when the relevant stimulus di-

The authors would like to thank Amanda Foster, Marland Pittman, Brian Turner, and Jim Whanger for the assistance in conducting these experiments and Bernhard Hommel, Raymond Klein, and Steven Mewaldt for their comments on an earlier version of the manuscript. Correspondence should be addressed to R. W. Proctor. Department of Psychological Sciences. Purdue University, West Lafayette, IN 47907-1364 (e-mail: proctor@psych.purdue.edu). mension also refers to location (e.g., the words left and right). It has been widely replicated and is found for visual and auditory stimuli and when irrelevant tones are presented to the left or right simultaneously with the presentation of visual stimuli in a constant, centered position (see Lu \& Proctor, 1995, and Simon, 1990, for reviews).

The Simon effect and related effects of irrelevant location information on performance have been investigated continuously since Simon's initial studies, becoming a central focus of much theoretical and empirical work on stimulus-response (S-R) compatibility in the 1990s (see, e.g., Psychological Research, 56 [April 1994], which is devoted exclusively to the Simon effect, and the extensive coverage given to the Simon effect in Hommel \& Prinz, 1997). There has been virtually complete agreement that the Simon effect is a function of spatial codes produced inadvertently at stimulus onset. Agreement has also been widespread--though not complete - that spatial coding has its influence primarily on response-selection processes through activation of the response-location code corresponding to that of the stimulus (e.g., Umiltà \& Nicoletti, 1990). Exactly how and why these spatial codes are produced, and the conditions under which the Simon effect will be observed, have been matters of some dispute (see Hommel \& Prinz, 1997; Lu \& Proctor, 1995).

An interesting exception to the finding that responses are faster when stimulus and response locations correspond was first reported by Hedge and Marsh (1975). They modified the standard two-choice task so that the response keys were designated by the colors of the two stimuli. This 

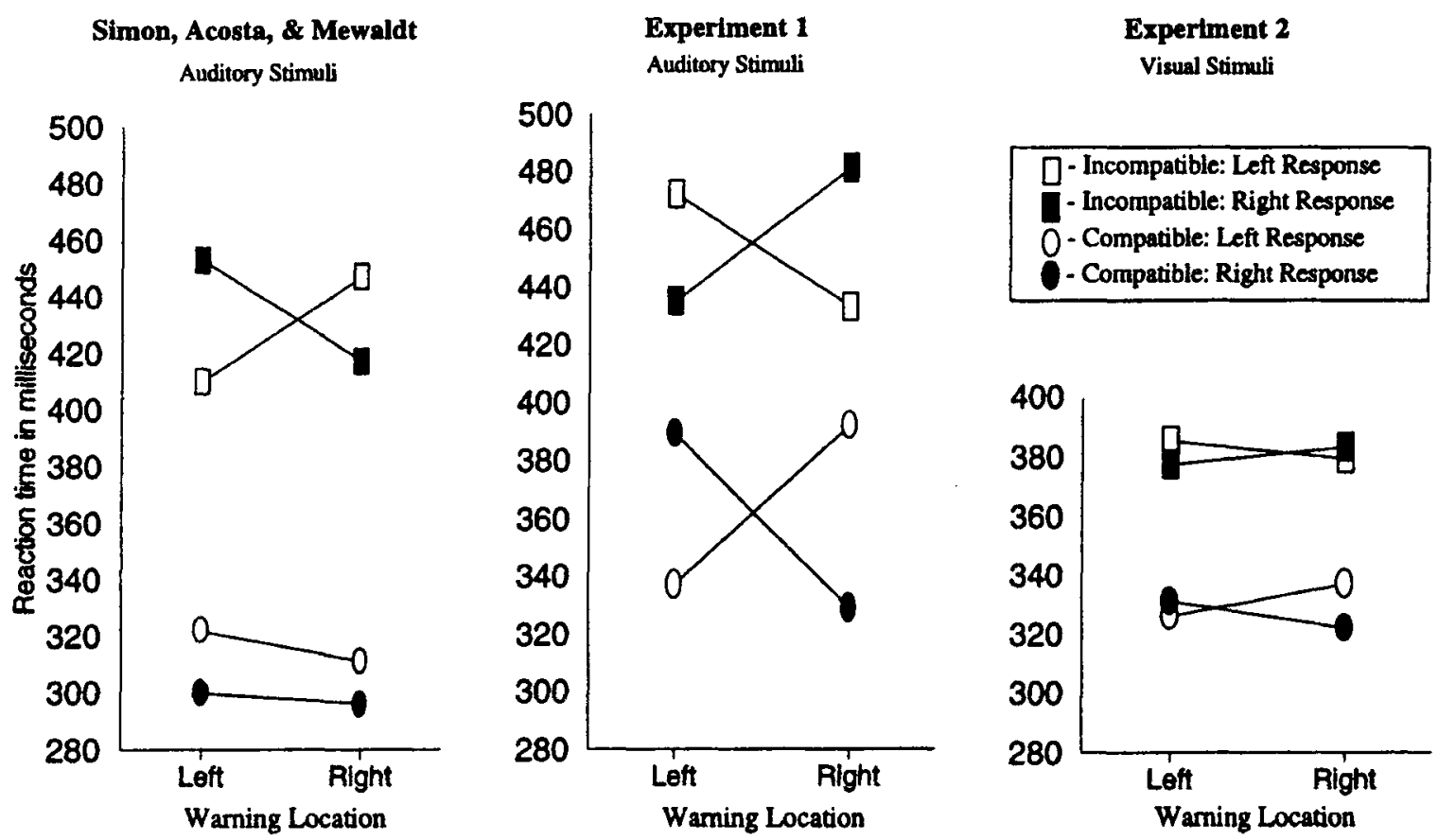

Figure 1. Mean reaction time (collapsed across delay) as a function of auditory warning location, response location, and mapping for Simon, Acosta, and Mewaldt's (1975) experiment and Experiments 1 and 2 of the present study. The data for Simon et al.'s experiment are means of median RTs obtained for each subject for the first block only, whereas our data are based on mean RTs for the individual subjects for both blocks. The pattern of results for our experiments does not change appreciably if the values are calculated in the manner done by Simon et al.

change allowed subjects to perform with either a compatible mapping of stimulus color to response color (press the red key to the red stimulus and the green key to the green stimulus) or an incompatible mapping (press the green key to the red stimulus and the red key to the green stimulus). The compatible mapping of $\mathrm{S}-\mathrm{R}$ colors yielded the standard Simon effect-that is, faster responses when stimulus and response locations corresponded than when they did not. However, the incompatible mapping yielded a reversed Simon effect-that is, responses were faster when the stimulus and response locations did not correspond than when they did. Hedge and Marsh attributed the reversed effect obtained with the incompatible $\mathrm{S}-\mathrm{R}$ color mapping to misapplication of a reversal rule (respond with the opposite of the stimulus value) to the irrelevant stimulus dimension. Although there has been disagreement regarding the explanation for the reversal, the phenomenon has been replicated consistently for both visual and auditory stimuli (e.g., Arend \& Wandmacher, 1987; De Jong, Liang, \& Lauber, 1994; Hasbroucq \& Guiard, 1991; Lu \& Proctor, 1994; Ragot \& Fiori, 1994; Ragot \& Guiard, 1992; Simon, Sly, \& Vilapakkam, 1981)

Simon, Acosta, and Mewaldt (1975) reported an experiment whose results stand in contrast to the established findings described above. Simon et al. conducted a task variant in which an auditory warning tone of $200 \mathrm{~Hz}$ was presented for $150 \mathrm{msec}$ in the left ear, the right ear, or both ears. This was followed by presentation of a $500-\mathrm{Hz}$ tone in one or the other ear to which the subject was to respond by pressing the response key (left or right) assigned to that stimulus location. In one block of trials, the delay between offset of the warning tone and onset of the imperative stimulus was $200 \mathrm{msec}$; in another, it was $400 \mathrm{msec}$. Presenting the irrelevant location information separate from the imperative stimulus allowed Simon et al. to vary the mapping of the relevant stimulus location to the response: Half of the subjects responded to the tone with a spatially compatible mapping, whereas half responded with a spatially incompatible mapping.

As shown in the left panel of Figure 1, there was no correspondence effect for warning-tone location and response location on RT when the S-R mapping was compatible. Warning-response correspondence did have a significant effect when the mapping was incompatible, but the effect was positive. That is, RT was faster when the warning and response locations corresponded than when they did not. This is in contrast to the reversed effect that typically is found for an incompatible mapping of the relevant S-R information with the Hedge and Marsh (1975) procedure.

Simon et al. (1975) proposed that the explanation for why the correspondence effect occurred with the incompatible mapping but not with the compatible mapping likely "lies in the relative strength of competing response tendencies" (p. 169). For the compatible mapping, the instructions to respond corresponded with a strong natural tendency to make the ipsilateral response rather than the 
contralateral response; thus, Simon et al. (1975) stated, "in this situation, then, any additional response tendency elicited by the warning tone was not potent enough to affect the balance between already unequal response tendencies associated with the stimulus" (p. 170). For the incompatible mapping, however, the instructions introduced a conflict between the tendency to make the instructed response and the one that was more natural; Simon et al. said, "in this situation involving relatively equal but competing responses to the stimulus, the added response tendency elicited by the warning tone was potent enough to produce a significant effect" (p. 170). In other words, according to Simon et al. (1975), the response tendency induced by the warning stimulus was sufficiently weak that it affected performance only when the relevant stimulus itself produced competing response tendencies.

Simon et al. (1975) noted that the absence of the correspondence effect with the compatible mapping was counter to their expectations based on the standard Simon task. That the incompatible mapping showed a positive correspondence effect, rather than a reversed effect, is equally surprising; however, Simon et al. (1975) had no reason to question this outcome, because the Hedge and Marsh (1975) study had yet to be published. Research since 1975 has established that irrelevant stimulus information of many types often produces large correspondence effects when it is presented several hundred milliseconds prior to the relevant information (e.g., Glaser \& Glaser, 1982; Lu, 1997; Sugg \& McDonald, 1994) and that the Hedge and Marsh reversal is widespread (see earlier references), serving to emphasize even further the deviance of Simon et al.'s results. Yet, as recently as 1990 , Simon devoted nearly 2 pages to describing the Simon et al. experiment and the interpretation of their results given above (Simon, 1990, pp. 53-54), without questioning them or pursuing them further. To our knowledge, no one else has evaluated them either.

The situation examined by Simon et al. (1975) requires further examination given the uniqueness of the outcomes they reported. If the findings are replicable, then some of the distinctive features of their procedure produce fundamental changes in the phenomena that are typically observed and may provide a key to understanding effects of irrelevant location information on performance. Simon et al.'s (1975) account focuses on the spatial nature of the relevant information in their study, but other distinctive features of their method that could be crucial include the administration of irrelevant location as a warning signal rather than as part of the test stimulus and presentation of two auditory stimuli on each trial. If Simon et al.'s (1975) findings are not replicable, then this apparent discrepancy should be duly noted, and their findings should not be regarded as reliable.

\section{EXPERIMENT 1}

Experiment 1 was a direct replication of Simon et al.'s (1975) study. Our method followed theirs closely, with the exception of the apparatus used to implement the experiment.

\section{Method}

Subjects. Forty undergraduate students, 24 males and 16 females, enrolled in introductory psychology courses at Purdue University participated in the experiment to satisfy in part a course requirement.

Apparatus and Stimuli. IBM-compatible PCs were used to generate and present all stimuli and record all responses. The experiment was programmed using the Micro Experimental Laboratory (MEL 2.0) software. All tones were presented through Koss TM101 headphones. The tone frequencies, intensities, and durations were similar to those used by Simon etal. (1975). The warning signal was a 150-msec, 200$\mathrm{Hz}$ warning tone presented to one ear or both ears. The binaural warning tones were presented at $82 \mathrm{~dB}$ (re .0002 dynes $/ \mathrm{cm}^{2}$ ) to each ear to approximate the loudness of the monaural warning tones, which were presented at $87 \mathrm{~dB}$ to one or the other ear. The imperative stimuli were monaural $500-\mathrm{Hz}$ tones presented to either ear at a sound pressure of $84 \mathrm{~dB}$. Responses were made by pressing the " $\mathrm{z}$ " or " " key of the standard computer keyboard with the left or right index finger, respectively.

Procedure. The procedure also followed that of Simon et al. (1975) closely. S-R mapping (compatible or incompatible) was manipulated between subjects. The subjects who performed with the compatible mapping were instructed to press the key at the location corresponding to that of the imperative stimulus, whereas the subjects who performed with the incompatible mapping were instructed to press the key at the opposite location. The subjects in both groups were told to ignore the low-pitch warning tone and to respond to the higher pitch stimulus tone that followed. They were also instructed to respond as fast as possible without making too many errors.

Each subject was tested individually in a small testing room. All subjects performed two blocks of 18 practice trials and 120 test trials. The blocks differed only in the length of the delay between warning and stimulus tones. In one block, a delay of $200 \mathrm{msec}$ intervened between the offset of the warning tone and the onset of the stimulus tone; in the other block, the delay was $400 \mathrm{msec}$. For each mapping group, half the subjects performed the 200 -msec block first, and half performed the 400-msec block first.

Each trial began with onset of the warning tone, followed after the appropriate delay by onset of the stimulus tone. This tone remained on until a response was made, and a new trial began $2 \mathrm{sec}$ later. Six types of trials were possible, involving three warning-tone locations (left ear, right ear, or both ears) and two stimulus-tone locations (left ear or right ear). Trial type was randomly selected without replacement for each 6-trial sequence.

RT was measured from the onset of the stimulus tone to the depression of a response key. RTs less than $100 \mathrm{msec}$ or longer than $1.5 \mathrm{sec}(<0.1 \%)$ were excluded from analysis, as were RTs for incorrect responses.

\section{Results and Discussion}

Mean correct RTs and percentages of errors (PEs) were computed for each subject for each condition. As is typical of studies in which spatial mapping is varied, the binaural warning trials showed a mapping effect. Responses were faster for the group who performed with the compatible mapping $(M \mathrm{~s}=367 \mathrm{msec})$ than for the group who performed with the incompatible mapping $(M \mathrm{~s}=475 \mathrm{msec})$ $\left[F(1,38)=12.63, M S_{\mathrm{e}}=7,814, p<.001\right]$. PE on the binaural trials did not differ significantly across the two mappings $(3.0 \%$ and $4.2 \%$ for the compatible and incompatible mappings, respectively) $\left[F(1,38)=0.72, M S_{\mathrm{e}}=19.71\right.$, $p=.403]$. Because the trials with a binaural warning tone were not of primary interest and the binaural tone was only approximately equated for loudness with the monaural tone, they were excluded from the main analyses. 
Table 1

Mean Reaction Times (RTs, in Milliseconds) and Percentages of Errors (PEs) as a Function of Mapping, Warning Location, Response Location, and Delay in Experiments 1 and 2

\begin{tabular}{|c|c|c|c|c|c|c|c|c|c|}
\hline \multirow[b]{3}{*}{ Mapping } & \multirow{3}{*}{$\begin{array}{l}\text { Warning } \\
\text { Location }\end{array}$} & \multicolumn{4}{|c|}{ 200-msec Delay } & \multicolumn{4}{|c|}{ 400-msec Delay } \\
\hline & & \multicolumn{2}{|c|}{ Left Key } & \multicolumn{2}{|c|}{ Right Key } & \multicolumn{2}{|c|}{ Left Key } & \multicolumn{2}{|c|}{ Right Key } \\
\hline & & RT & $\mathrm{PE}$ & RT & PE & $\mathrm{RT}$ & $\mathrm{PE}$ & RT & $\mathrm{PE}$ \\
\hline \multicolumn{10}{|c|}{ Experiment 1} \\
\hline \multirow[t]{2}{*}{ Incompatible } & Left & 469 & 5.00 & 434 & 4.25 & 474 & 6.25 & 436 & 2.75 \\
\hline & Right & 440 & 5.00 & 481 & 7.75 & 426 & 3.25 & 481 & 6.25 \\
\hline \multirow[t]{2}{*}{ Compatible } & Left & 330 & 1.25 & 376 & 6.50 & 343 & 1.25 & 401 & 6.25 \\
\hline & Right & 380 & 8.50 & 317 & 1.25 & 403 & 6.50 & 340 & 0.25 \\
\hline \multicolumn{10}{|c|}{ Experiment 2} \\
\hline \multirow[t]{2}{*}{ Incompatible } & Left & 380 & 2.75 & 372 & 1.50 & 391 & 0.50 & 382 & 1.25 \\
\hline & Right & 376 & 1.50 & 377 & 2.50 & 381 & 2.00 & 389 & 1.75 \\
\hline \multirow[t]{2}{*}{ Compatible } & Left & 317 & 1.00 & 331 & 0.75 & 335 & 1.00 & 332 & 0.50 \\
\hline & Right & 336 & 1.00 & 318 & 0.25 & 337 & 1.25 & 326 & 0.50 \\
\hline
\end{tabular}

For the main analyses, the data were examined as a function of warning location (left, right), response location (left, right), delay ( $200 \mathrm{msec}, 400 \mathrm{msec}$ ), and mapping (compatible, incompatible), with all but the last factor being within-subject variables. The mean RT and PE data as a function of these variables are shown in Table 1, with the mean RTs collapsed across delay also plotted in the center panel of Figure 1.

Reaction time. Like the binaural warning trials, the monaural trials showed a significant main effect of mapping $\left[F(1,38)=14.24, M S_{\mathrm{e}}=49,598, p<.001\right]$. Responses were slower with the incompatible mapping $(M=$ $455 \mathrm{msec})$ than with the compatible mapping $(M=$ $361 \mathrm{msec})$. The only other term that exceeded the .05 probability level was the three-way interaction of warning location $\times$ response location $\times$ mapping $[F(1,38)=$ 28.37, $M S_{\mathrm{e}}=7,013, p<.001 \mathrm{]}$. As is evident in Figure 1, with the compatible mapping, responses were faster when warning location and response location corresponded $(M=333 \mathrm{msec})$ than when they $\operatorname{did}$ not $(M=390 \mathrm{msec})$ $\left[F(1,19)=28.48, M S_{\mathrm{e}}=4,664, p<.001\right]$, but, with the incompatible mapping, responses were faster when warning location and response location did not correspond $(M=$ $434 \mathrm{msec})$ than when they $\operatorname{did}(M=476 \mathrm{msec})[F(1,19)=$ $\left.7.58, M S_{\mathrm{e}}=9,363, p=.013\right]$.

Percentage of errors. The only significant effect for the error data was the three-way interaction of warning location $\times$ response location $\times$ mapping $[F(1,38)=18.12$, $\left.M S_{\mathrm{e}}=78.598, p<.001\right]$. Consistent with the RT data, the error rate was lower when warning location and response location corresponded $(M=1.0 \%)$ than when they did not $(M=6.9 \%)$ for the compatible mapping group $\left[F(1,19)=13.92, M S_{\mathrm{e}}=101.275, p<.00 \mathrm{I}\right]$, with the incompatible mapping group showing the reversed relation $(M \mathrm{~s}=6.3 \%$ and $3.8 \%$, respectively) $[F(1,19)=4.47$, $\left.M S_{\mathrm{e}}=55.921, p=.048\right]$.

Summary. The results of Experiment 1 are unambiguous. The pattern of results reported by Simon et al. (1975) - no warning-response correspondence effect with a compatible $S-R$ mapping and a positive warningresponse correspondence effect with an incompatible mapping-was not replicated. Instead, the results conformed to the pattern expected on the basis of numerous related studies. When the $\mathrm{S}-\mathrm{R}$ mapping was spatially compatible, the warning tone produced a correspondence effect similar to the Simon effect that occurs when stimulus location is irrelevant to the task. When the mapping was spatially incompatible, the warning tone produced a reversed correspondence effect, much as occurs for an incompatible mapping of the relevant stimulus dimension in the Hedge and Marsh (1975) task. Although Simon et al. (1975) tested each subject at both 200- and 400-msec delays, as we did, they reported data only for the first delay that was tested, and they analyzed median RTs rather than mean RTs. We also analyzed median RTs for each subject in only the first delay that each received, and the result pattern did not change appreciably from the analysis of means for both sessions that we report in detail. Because the outcomes we obtained conform to widely replicated findings in the literature, they can be accorded a relatively high degree of confidence.

\section{EXPERIMENT 2}

Even though our results are in agreement with the majority of the literature, we thought it best to replicate these findings in a slightly different task version. A Simon effect is produced when an irrelevant left or right tone occurs simultaneously with a visual imperative stimulus, in what is called the accessory stimulus version of the Simon task (e.g., Stoffels, van der Molen, \& Keuss, 1989). By using left or right location as the relevant dimension for the visual stimuli, it was possible to use in Experiment 2 the same method as in Experiment 1, with the exception of the imperative stimuli being visual rather than auditory. Our expectation was that the same qualitative pattern of warning-tone location effects would be observed as in Experiment 1, albeit with the magnitude reduced because the warning stimulus was in a different sensory modality than the imperative stimulus.

\section{Method}

Forty new undergraduate students, 18 males and 22 females, from the same introductory psychology pool as in Experiment 1 participated in the experiment. The method was the same as that of Experiment 1 in all respects except that the imperative stimuli were presented visually 
They were white circles, presented against the dark background of a 14-in. VGA computer screen, displayed to the left or right. The circles measured $0.64 \mathrm{~cm}$ in diameter, and the distance between centers for the left and right locations was $12 \mathrm{~cm}$. When viewed from approximately $55 \mathrm{~cm}$, the visual angles were $0.67^{\circ}$ and $12.31^{\circ}$, respectively.

\section{Results and Discussion}

The binaural warning trials showed a typical spatial compatibility effect, with responses being faster and more accurate with the compatible S-R mapping $(M \mathrm{~s}=$ $325 \mathrm{msec}$ and $0.6 \%$ ) than with the incompatible mapping $(M \mathrm{~s}=384 \mathrm{msec}$ and $1.8 \%)[F \mathrm{~s}(1,38)=12.29$ and 3.59 , $M S_{\mathrm{e}} \mathrm{s}=2,823$ and $3.528, p \mathrm{~s}=.001$ and .066$]$. As in $\mathrm{Ex}-$ periment 1 , the primary analyses examined performance on trials with monaural warning tones as a function of warning location, response location, delay, and mapping. Mean RTs and PEs for these analyses are shown in the bottom half of Table 1, with the RT data collapsed over delay also plotted in the right panel of Figure 1.

Reaction times. Responses were slower with the incompatible mapping ( $M=381 \mathrm{msec})$ than with the compatible mapping $(M=329 \mathrm{msec})\left[F(1,38)=9.33, M S_{\mathrm{e}}=\right.$ $23,265, p<.005]$. More importantly, the three-way interaction of warning location $\times$ response location $\times$ mapping was significant $\left[F(1,38)=14.67, M S_{\mathrm{e}}=379\right.$, $p<.001]$. The pattern was similar to that of Experiment 1 , only reduced in magnitude. With the compatible mapping, responses were faster when warning location and response location corresponded $(M=324 \mathrm{msec})$ than when they did not $(M=334 \mathrm{msec})[F(1,19)=15.18$, $\left.M S_{\mathrm{e}}=266, p<.001\right]$, whereas, with the incompatible mapping, there was a tendency toward responses being faster when warning and response location did not correspond $(M=378 \mathrm{msec})$ than when they did $(M=384 \mathrm{msec})$ $\left[F(1,19)=3.56, M S_{\mathrm{e}}=491, p=.074\right]$.

Percentage of errors. No terms were significant in the analysis of the PE data. Only the main effect of mapping had a probability less than $.10\left[F(1,38)=2.96, M S_{\mathrm{e}}=\right.$ $23.479, p=.092]$. The PE tended to be less for the compatible mapping $(M=0.8 \%)$ than for the incompatible mapping $(M=1.7 \%)$.

Comparison to Experiment 1. The results of Experiment 2 were compared with those of Experiment 1 because the two experiments differed only in whether the imperative stimulus was presented visually or auditorily. Analyses were conducted on the RT and PE data with experiment ( 1 and 2 ) and mapping (compatible, incompatible) as between-subject factors and warning-response correspondence (corresponding, noncorresponding) as a within-subject factor. Main effects of experiment were obtained for both RT and PE $[F \mathrm{~s}(1,76)=12.30$ and 24.91 , $M S_{\mathrm{e}} \mathrm{s}=9,077$ and $17.124, p \mathrm{~s}<.001$, respectively], indicating that responses were slower and less accurate in Experiment $1(M \mathrm{~s}=408 \mathrm{msec}$ and $4.5 \%)$ than in Experiment $2(M \mathrm{~s}=355 \mathrm{msec}$ and $1.25 \%)$. The only other term involving experiment that was significant for both dependent measures was the experiment $\times$ mapping $\times$ correspondence interaction $[F \mathrm{~s}(1,76)=18.51$ and 15.17 , $M S_{\mathrm{e}} \mathrm{s}=921$ and $10.383, p \mathrm{~s}<.001$, respectively, for $\mathrm{RT}$ and PE]. The three-way interactions indicate that warningresponse correspondence exerted a larger effect in Experiment 1 , in which both the warning and imperative stimuli were auditory, than in Experiment 2, in which the warning stimulus was auditory and the imperative stimulus visual.

Summary. Performance was faster and more accurate on average in Experiment 2, in which the imperative stimuli were visual, than in Experiment 1, in which they were auditory. The major finding, however, is that the visual stimulus version of the task produced a pattern of correspondence effects similar to, though of lesser magnitude than, that of our Experiment 1 and dissimilar to that reported by Simon et al. (1975). Thus, the warning tone elicits a tendency to make the corresponding response when the mapping is compatible and the noncorresponding response when the mapping is incompatible, even when the imperative stimulus is presented visually.

\section{GENERAL DISCUSSION}

The present experiments failed to replicate either of the main aspects of Simon et al.'s (1975) results. Instead of there being no correspondence effect for warning-tone location and response location with a compatible mapping of the relevant stimulus to keypresses, we found faster responses when warning and response location corresponded than when they did not (i.e., a positive correspondence effect). Instead of finding a positive correspondence effect for warning tone and response location with an incompatible mapping of the relevant stimulus to the keypresses, we found faster responses when warning and response location did not correspond than when they did (i.e., a negative correspondence effect). This pattern of results was obtained both in a direct replication of Simon et al.'s (1975) experiment in which the imperative stimulus was presented auditorily and in a conceptual replication in which the stimulus was presented visually. The reduced magnitude of the effects in the latter case is not surprising given that the warning tone was in a different modality than was the imperative stimulus.

Because Simon et al.'s (1975) findings are at odds with the results of most studies that have used related procedures, they might well have provided an important lead toward explaining the effects of irrelevant location information on performance, had they proved reliable. But they did not prove to be so. We cannot eliminate entirely the possibility that there is a subtle procedural difference that accounts for their deviant findings, but we think it most likely that this is not the case. Positive spatial correspondence effects have been obtained not only when the relevant stimulus dimension is nonspatial (i.e., the Simon effect) but also when it signifies locations and is mapped compatibly to responses (i.e., the spatial Stroop task; e.g., relevant stimuli are the words left or right; see Lu \& Proctor, 1995). Moreover, when the irrelevant location information is conveyed by arrows, which act in many respects like locations (e.g., Eimer, 1995; Wang \& Proctor, 1996), correspondence effects have been obtained when the irrelevant information precedes the relevant information by time intervals in the range examined by Simon et al. (1975) and in the present study (Lu, 1997). Similarly, negative (or reversed) S-R correspondence effects-that is, faster responding when stimulus and response locations do not correspond-have been obtained when the relevant stimulus information is spatial and the $\mathrm{S}-\mathrm{R}$ mapping is incompatible (Arend \& Wandmacher, 1987; Lu \& Proctor, 1994). The reversal has not only been obtained with visual stimuli but also with auditory stimuli (Ragot \& Fiori, 1994; Ragot \& Guiard, 1992). In sum, the literature offers little to suggest that a subtle procedural factor accounts for the discrepancy of Simon et al.'s results from ours.

The results from our experiments, and those from the studies mentioned in the previous paragraph, also undermine the specific explanation proposed initially for their findings by Simon et al. (1975) and reiterated by Simon (1990). Specifically, Simon et al. (1975) proposed 
that the activation of the corresponding response produced by the warning stimulus was sufficiently weak that it could influence performance only when the relevant stimulus itself did not produce unequivocal activation of the assigned response (i.e., with the incompatible mapping). Our findings with the compatible mapping demonstrate in contrast that the response activation produced by the warning stimulus is sufficient to affect performance. More generally, whether provided by a warning tone or by some other means, the response activation produced by irrelevant information produces a correspondence effect when a relevant stimulus dimension signifying location is mapped compatibly to responses ( $\mathrm{Lu} \&$ Proctor, 1995). The second part of Simon et al.'s explanation-that the warning stimulus activates the corresponding response when the relevant $S-R$ mapping is incompatible- is also contradicted by our findings. Instead, the response at the noncorresponding location receives activation. More generally, the $S-R$ correspondence effect for irrelevant location information is reversed when an incompatible mapping rule is in effect, regardless of whether the irrelevant information is included in the imperative stimulus or in a warning tone (e.g., Arend \& Wandmacher, 1987).

In sum, we failed to replicate the distinct and unique pattern of findings reported by Simon et al. (1975). Given that we did not obtain the results they reported and that our results are in close accord with those of studies that have used related procedures, the findings of Simon et al. should be disregarded. Unless conditions are established that allow the pattern reported by Simon et al. (1975) to be reproduced reliably, which we think unlikely, the warning-location task should be viewed as producing results that are in agreement with closely related procedures.

\section{REFERENCES}

AREND, U., \& WANDMACHER, J. (1987). On the generality of logical recoding in spatial inference tasks. Acta Psychologica, 65, 193-210

De Jong, R., Liang, C.-C., \& Lauber, E. (1994). Conditional and unconditional automaticity: A dual-process model of effects of spatia stimulus-response correspondence. Journal of Experimental Psychology: Human Perception \& Performance, 20, 731-750.

EIMER, M. (1995). Stimulus-response compatibility and automatic response activation: Evidence from psychophysiological studies. Journal of Experimental Psychology: Human Perception \& Performance, 21, 837-854.

Glaser, M. O., \& Glaser, W. R. (1982). Time course analysis of the Stroop phenomenon. Journal of Experimental Psychology: Human Perception \& Performance, 8, 875-894.

Hasbrouce, T., \& Guiard, Y. (1991). Stimulus-response compatibility and the Simon effect: Toward a conceptual clarification. Journal of Experimental Psychology: Human Perception \& Performance, 17, 246-266.

Hedge, A., \& MARSH, N. W. A. (1975). The effect of irrelevant spatial correspondences on two-choice response time. Acta Psychologica, $39,427-439$.
Hommel, B., \& Prinz, W. (EDs.) (1997). Theoretical issues in stimulusresponse compatibility. Amsterdam: North-Holland

Lu, C.-H. (1997). Correspondence effects for irrelevant information in choice-reaction tasks: Characterizing the S-R relations and the processing dynamics. In B. Hommel \& W. Prinz (Eds.), Theoretical issues in $S-R$ compatibility (pp. 85-117). Amsterdam: North-Holland.

Lu, C.-H., \& Proctor, R. W. (1994). Processing of an irrelevant location dimension as a function of the relevant stimulus dimension. Journal of Experimental Psychology: Human Perception \& Performance, 2, 286-298.

Lu, C.-H., \& Proctor, R. W. (1995). The influence of irrelevant location information on performance: A review of the Simon and spatial Stroop effects. Psychonomic Bulletin \& Review, 2, 174-207.

RaGot, R., \& FIORI, N. (1994). Mental processing during reactions toward and away from a stimulus: An ERP analysis of auditory congruence and S-R compatibility. Psychophysiology, 31, 439-446.

RAGOT, R., \& GUIARD, Y. (1992). Stimulus congruence and stimulusresponse compatibility: Two variables disentangled in an auditory RT task. European Journal of Cognitive Psychology, 4, 219-232.

Simon, J. R. (1990). The effects of an irrelevant directional cue on human information processing. In R. W. Proctor \& T. G. Reeve (Eds.), Stimulus-response compatibility: An integrated perspective (pp. 31-86). Amsterdam: North-Holland

Simon, J. R., Acosta, E., JR., \& MEWALdT, S. P. (1975). Effect of locus of warning tone on auditory choice reaction time. Memory \& Cognition, 3, 167-170.

Simon, J. R., \& RUdELL, A. P. (1967). Auditory S-R compatibility: The effect of an irrelevant location cue on information processing. Journal of Experimental Psychology, 51, 300-304.

Simon, J. R., SLY, P. E., \& VilapakKam, S. (1981). Effect of compatibility of S-R mapping on reaction toward the stimulus source. Acta Psychologica, 47, 63-81.

Stoffels, E. J., van der Molen, M. W., \& Keuss, P. J. G. (1989). An additive factors analysis of the effects of location cues associated with auditory stimuli on stages of information processing. Acta Psychologica, 70, 161-197.

SugG, M. J., \& MCDonald, J. E. (1994). Time course of inhibition in color-response and word-response versions of the Stroop task. Journal of Experimental Psychology: Human Perception \& Performance, 20, 647-675.

Umiltà, C., \& Nicolettr, R. (1990). Spatial stimulus-response compatibility. In R. W. Proctor \& T. G. Reeve (Eds.), Stimulus-response compatibility: An integrated perspective (pp. 89-116). Amsterdam: North-Holland.

Wang, H., \& Proctor, R. W. (1996). Stimulus-response compatibility as a function of stimulus code and response modality. Journal of Experimental Psychology: Human Perception \& Performance, 22, 1201-1217

(Manuscript received April 11, 1997; revision accepted for publication July 21, 1997.) 